\title{
Habitat Analysis of Endangered Korean Long-Tailed Goral (Naemorhedus caudatus raddeanus) with Weather Forecasting Model
}

\author{
Sanghun Lee ${ }^{1}$, Baek-Jun Kim ${ }^{1}$ and Kon Joon Bhang ${ }^{2, *(1)}$ \\ 1 National Institute of Ecology, Seocheon 33657, Korea; sanghunlee@nie.re.kr (S.L.); \\ naturalist71@gmail.com (B.-J.K.) \\ 2 Department of Civil Engineering, Kumoh National Institute of Technology, Gumi 39177, Korea \\ * Correspondence: bhang.1@kumoh.ac.kr
}

Received: 16 August 2019; Accepted: 23 October 2019; Published: 1 November 2019

check for updates

\begin{abstract}
Climate simulation is often used for evaluation of the sustainability of a species in global scale but not applicable for our study because the global data is too coarse to be used in small and fragmented habitat areas. We examined a weather forecasting model for the habitat analysis of the endangered species of the Korean long-tailed goral (Naemorhedus caudatus raddeanus). The weather research forecasting (WRF) model is implemented to downscale global climate data for a small fragmented habitat of the goral. The coordinates of goral fecal samples were collected during winter 2005 and summer 2006 using GPS and the goral habitat was set with the elevations of fecal samples mostly found. The atmospheric parameters of the habitat were then simulated by WRF and defined as the atmospheric signature of the goral suitable habitat. A series of temperature changes was then projected for the period from 2010s to 2090s to evaluate the change of the habitat for summer (June) and winter (December) seasons. As a result, the suitable habitat of the Korean long-tailed goral would be significantly declined and almost disappeared in the 2070s for summer or 2050s for winter under the climate scenarios of RCP 8.5 by IPCC.
\end{abstract}

Keywords: habitat analysis; climate impact; weather forecasting; endangered species; Korean long-tailed goral; downscaling

\section{Introduction}

One of the most serious environmental outcomes of climate change involves threats to the habitats of living organisms and entire ecosystems. This influence on living organisms tends to increase extinction rates for some vulnerable species and cause serious regional or global modification of biodiversity [1-4]. In general, the responses of living organisms to climate change are often difficult to investigate because environmental changes and the associated responses in nature are slow and occur over long periods. However, in recent years the rates of such changes have been too rapid for living organisms to adapt to, and therefore the most immediate responses might be a shift in geographical range or, for an endangered species, possible extinction.

Many studies have examined the possible impacts of climate change on the habitats and populations of species. Each species is able to survive only under a specific set of climatic conditions termed a climate envelope [3]. As climate change proceeds via temperature increase, species move to higher elevations and/or latitudes for survival, so habitats are frequently contracted as the areas of climatically suitable habitat decline [5-13] because climate and topographic features are major influences on species distributions and connectivity of populations [14-16]. For example, based on projections of $4{ }^{\circ} \mathrm{C}$ temperature increase, species might migrate more than $500 \mathrm{~km}$ toward the poles (or $500 \mathrm{~m}$ higher 
in elevation) seeking suitable climatic conditions such as temperature and precipitation [17]. Global average temperature increase of $2{ }^{\circ} \mathrm{C}-3{ }^{\circ} \mathrm{C}$ may also cause an extinction of $20 \%-30 \%$ of species around the world [18] because species sensitive to environmental changes and having low dispersal ability are typically vulnerable to fragmentation and urbanization due to climate and landscape changes [19]. Since current climate trends will not be reversed in a short term, habitat protection, preservation, and restoration of endangered species are a central challenge in the sustainability of natural systems throughout the world. Especially endangered species occupying small geographic areas may be more vulnerable to climate change [20]. The impact of climate change is almost universal so understanding the suitable climate envelopes of endangered species for future might provide useful information on effects of climate change on habitat or geographical distribution of species. The best approach for this purpose is using climate scenarios by modeling [21,22].

There are numerous studies of habitat analyses associated with climate models to understand the impact on habitats and populations for endangered species. For example, the giant panda has significantly lost its habitat due to agricultural conversion, road construction, logging, mining, etc. so that habitats are fragmented and isolated resulting in hindering gene diversity causing the increase of extinction rate. Moreover, current climate change threatens the sustainability of the giant panda. As a result, the giant panda will be significantly reduced by nearly $60 \%$ over 70 years by climate change causing a habitat shift to higher elevations and latitudes [23].

The Korean long-tailed goral faces the similar situation of the giant panda. It is registered in the IUCN Red List of Threatened Species [24] and Convention on International Trade in Endangered Species (CITES) Appendices I [25] that lists the most endangered species among CITES-listed wild animal and plants. Studies noted that the Korean long-tailed goral is distributed across northeast Asia, eastern Russia, northeastern China, and the Korean peninsula and currently exists only in high mountain areas such as Seorak, Yanggu, Hwacheon, demilitarized zone (DMZ), Uljin, and Samcheok in Korea [24] and the goral population was approximately 690-784 individuals after a national survey in 2002 and a hundred of them were known to inhabit in Mt. Seorak [26]. A more recent survey reported that 150-200 individuals reside in the mountains [27]. According to [28], proximately 6000 individuals were captured during heavy snowfall in Gangwon Province on March, 1964 and February, 1965. The fossil study on the goral by [29] explained that the goral was distributed in much wider and lower areas in the Korean peninsula but range shift and fragmentation was mainly due to hunting during the Pleistocene. Human disturbance by hunting shifted goral habitats to higher elevations with rocky hills and this had naturally led habitats to become fragmented. Even though the natural enemies of tigers and leopards had already disappeared in early 1960s, the goral was steadily reduced [30] and recently increased with the effort of restoration projects by the government [31]. However, the goral is still in a vulnerable state because climate change became another threat increasing the potential of the extinction rate. The main distribution of the Korea long-tailed goral is known to be $32 \%$ in forest and $31 \%$ in valley [32]. The goral was found to prefer the north-west aspect, $30^{\circ}-35^{\circ}$ of slope, $500 \mathrm{~m}$ of elevation, $50 \mathrm{~m}$ of distance from water resources in summer, and $100 \mathrm{~m}$ away from roads from the study using a GPS collar [33].

Climate is important in terms of the sustainability of the species so combining to habitat analyses can provide useful information in understanding or examining the destiny of habitats for endangered species. Unfortunately, there are challenges in using climate simulation models in habitat analysis. Climate modeling schemes mostly cover the globe, so that input datasets are usually too coarse to be applied to smaller areas and are difficult to downscale global climate datasets. Periodically measured or sampled data for a species over a long period are also very difficult to be obtained: in many cases, the data are typically discontinued within a few years.

Although the Korean long-tailed goral faces possible extinction, there are no studies on the possible impact of climate change on the goral habitat and population with climate model or scenarios. Since climate models are not appropriate for fragmented small areas of the goral, we used an approach that permits meso- or micro-scale weather forecasting to evaluate the impact of climate change to 
the Korean long-tailed goral habitat for future. The details of this study include: (1) examining the modeling sensitivity and reliability by comparing resulting parameters, i.e., temperature, relative humidity, and wind speed and direction with measured weather datasets, (2) evaluating habitat change with limited information on the Korean long-tailed goral by comparing current climatic conditions with future climate parameter of temperature, and (3) evaluating direct impacts of selected climate scenarios on the future goral habitat and indirect impacts on the goral population.

\section{Study Area}

The study area is the Seoraksan National Park (Figure 1) in Inje, Gangwon Province, South Korea, which covers an area of $398.5 \mathrm{~km}^{2}$ and has a summit elevation of $1708 \mathrm{~m}$. The national park is a part of a mountainous range called Taebaek, which encompasses the east side of the Korean peninsula from north to south, and includes long, well developed V-shape valleys with temporary or permanent streams. Mount Seorak is the third-highest peak in Korea and is typically covered with snow before the middle of October due to the high elevation. This area is representative of the virgin forests with sub-Alpine flora that occur in the temperate region around the middle of the peninsula. The area was designated as a natural reserve in 1965 and then as a national park in 1970. The park was also designated as a Biosphere Reserve by UNESCO in 1982 due to its unique biome with many rare taxa of flora and fauna and beautiful scenery.
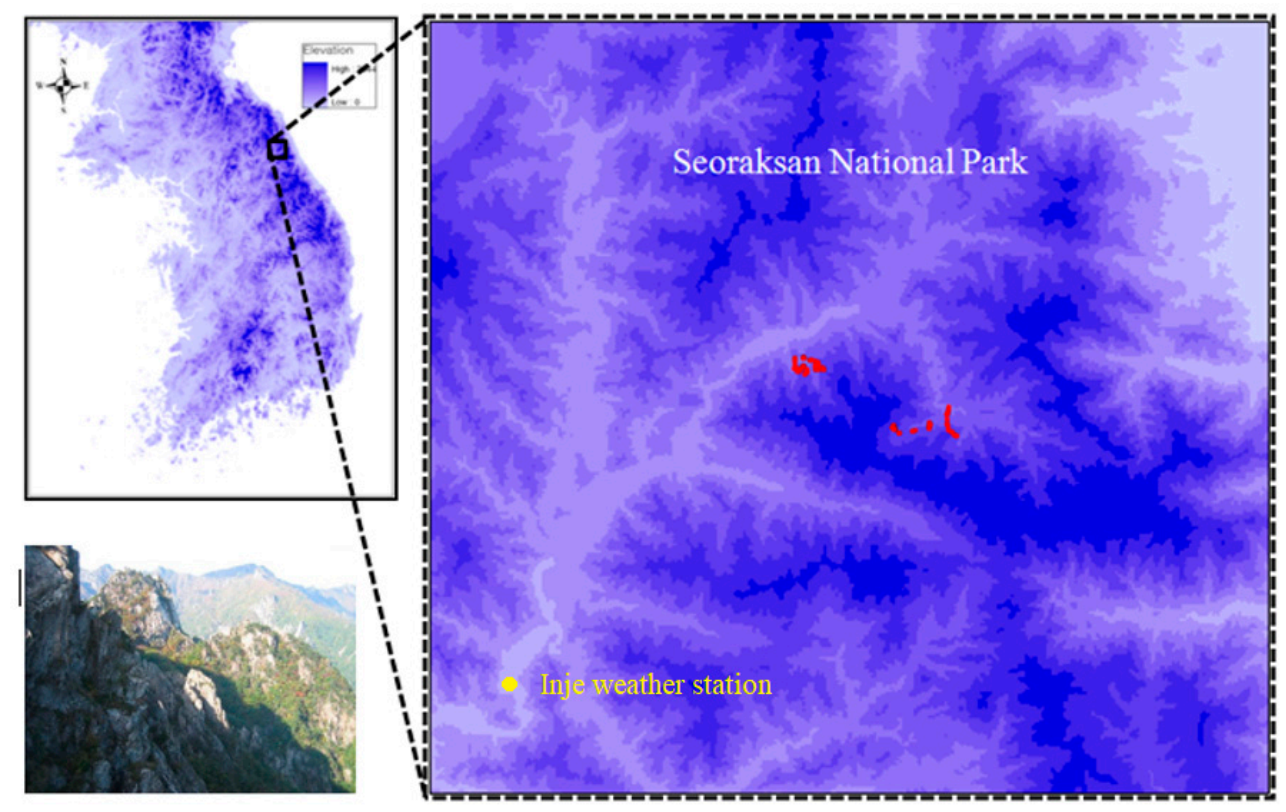

Figure 1. Maps of the location and sampling sites in Seoraksan National Park. The red marks indicate the sampling sites of fecal deposits of the Korean long-tailed goral and the yellow star is the location of the Inje weather station approximately $20 \mathrm{~km}$ far away from the sample sites.

\section{Materials and Methods}

The datasets used in the study were goral fecal sample locations from GPS, global climate data, and weather data collected in a local weather station (for an overview, see Figure 2). The fecal sample locations were used to define the past and current goral habitat region in the national park. With the Weather Research and Forecasting (WRF) model, the regional weather parameters were estimated as the past and current suitable habitat climate conditions. After the sensitivity test of the model, the current climate condition was projected. The past climate condition was then compared to measured weather data from the Inje weather station for the sensitivity test of the model. The current climate condition was used as a reference of the current goral habitat climate condition. Using the climate projection algorithm called Modified Korean Parameter-elevation Regressions on Independent Slope 
Model (MK-PRISM), the climate condition of the goral habitat was projected and compared to the current habitat area. Detailed descriptions were described in the following sections.

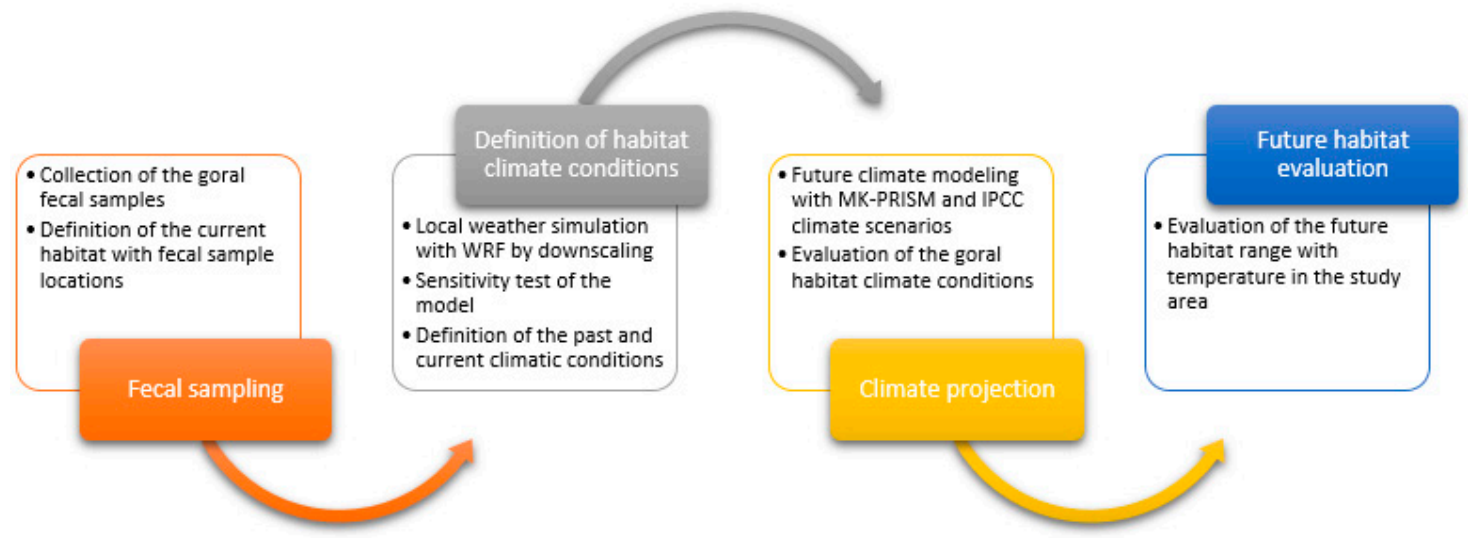

Figure 2. Data procedure and brief descriptions of the study with the numerical weather projection model of weather research and forecasting (WRF) and habitat evaluation by climate projection.

\subsection{Fecal Samples of the Goral}

We designed four routes to collect goral fecal deposits, and more than 160 samples were collected within $1 \mathrm{~m}$ either side of the routes using the transect line census method. Of those deposits, 112 were collected along two routes during the beginning of the winter in 2005 (December 16 and 17) and the rest (52 deposits) were along the other two routes during the beginning of the summer in 2006 (July 4 and 6). The collected samples were maintained in fresh, soft, and wet conditions, which suggest that the feces might have been deposited within 1 or 2 weeks. At the same time, all of the deposit coordinates were recorded with a global positioning system (GPS) and tabulated to locate the current habitat area with ArcGIS.

\subsection{Brief Description of the WRF Model}

A weather forecasting model called weather research and forecasting (WRF) is featured as a next-generation meso-scale numerical weather prediction system with functionalities of data assimilation, parallel computation, and system extensibility [34]. The system was developed jointly by the National Center for Atmospheric Research (NCAR), the National Oceanic and Atmospheric Administration, the Air force Weather Agency (AFWA), the Naval Research Laboratory, the University of Oklahoma, and the Federal Aviation Administration (FAA). One of the key features of WRF is nesting domains, which means domains can be easily communicated to a finer grid domain from the coarser parent domain and vice versa. Therefore, WRF is appropriate for forecasting climatic parameters (i.e., temperature, precipitation, etc.) in the meso-scale (regional) or micro-scale climate applications [35], such as our study case for the goral habitat analysis in small fragmented areas in Seoraksan National Park.

For the weather simulation, WRF is used to retrieve future climate temperature in a fragmented small habitat area of the goral and applied for examining the change of the current habitat range. The model was combined with the climate scenario of the representative concentration pathway (RCP) 8.5 in the IPCC Fifth Assessment Report (AR5) of 2014 [36].

\subsection{Computer Simulation for Weather Parameters}

The regional weather forecasting model (WRF ver. 3.9) retrieved climatic variables of temperature, relative humidity, wind speed and direction, etc. The global climate data collected in every $6 \mathrm{~h}$ with $1^{\circ}$ spatial resolution from the National Center for Environmental Projection (NCEP) Final (FNL) Operational Global Analysis (OGA) data were utilized for the initial boundary condition. The WRF simulation was executed for 31 days including two specific moments of 00 UTC on December 1, 2005 
for winter and 00 UTC on June 1, 2006 for summer at a time interval $(\Delta t)$ of $180 \mathrm{~s}$. Since the NCEP input data resolution of $1^{\circ}$ was very coarse for the meso- or micro-scale simulation for this study, domains were downscaled into two-way quadruple nested domains of $27,9,3$, and $1 \mathrm{~km}$ with the grid sizes of $70 \times 70,70 \times 70,70 \times 70$, and $130 \times 130$ in WRF, respectively, with 27 vertical levels (Figure 3) using the advance research WRF (ARW) algorithm [37,38]. The simulation outputs were then produced every $6 \mathrm{~h}$ with the cumulus parameterization scheme by [39]; the WRF Single Moment 6-Class Microphysics Scheme (WSM6) for the cloud physical process in the simulation $[40,41]$ and the Mellor-Yamada-Janjic PBL scheme [42,43] were adopted to parameterize turbulences in the planetary boundary layer (PBL). After the simulation, the sample site temperature was extracted based on coordinates and were compared to measurements from the Inje weather station, approximately $20 \mathrm{~km}$ away from the study sites to the north-west direction of the national park, to test the sensitivity and the applicability of the model.

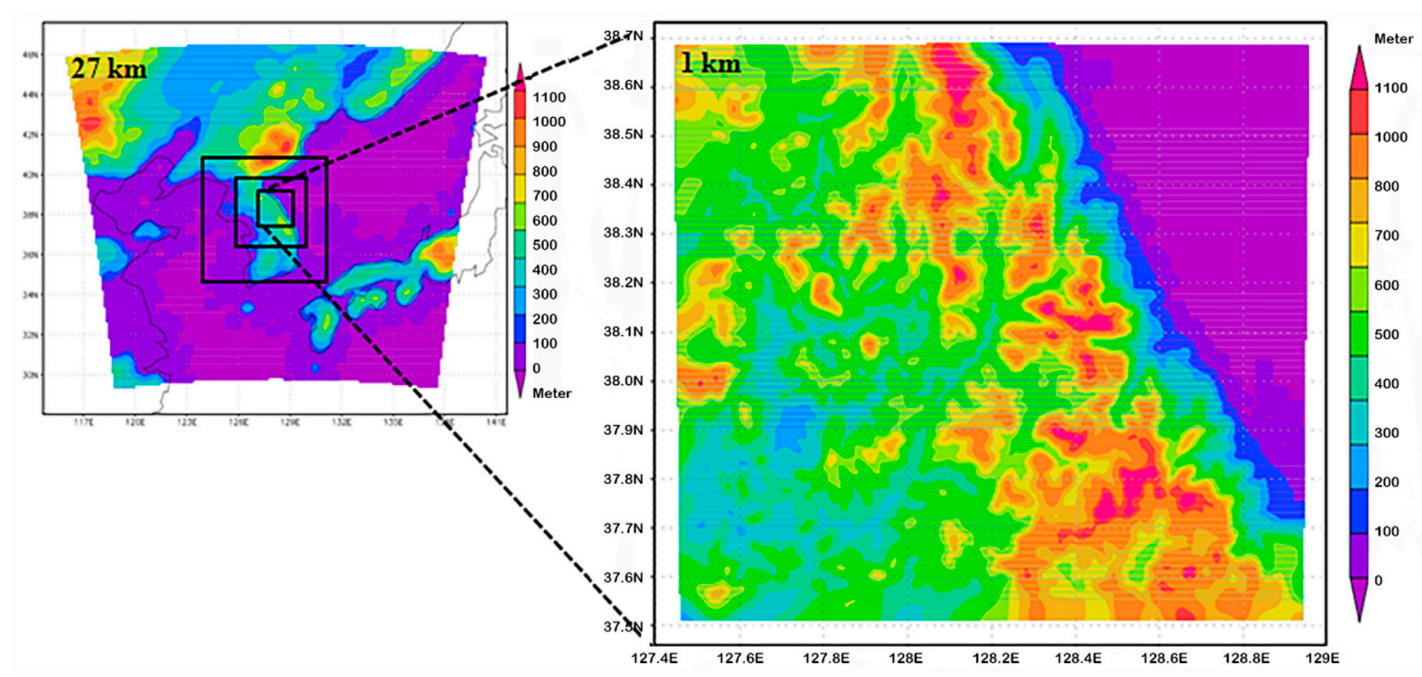

Figure 3. Elevation map illustrating the two-way quadrupled nested domains of numerical modeling for resolutions of $27 \mathrm{~km}$ (left) and $1 \mathrm{~km}$ after several downscaling steps (see 3.4 for more details).

\subsection{Climate Modeling for Future Habitat Climate Analysis}

RCP8.5 in AR5 by IPCC were used to assess the future climate of the goral habitat [36]. The climate scenario is originally provided by Regional Climate Model (RCM) Hadley center Global Environmental Model version 3-Regional Atmosphere (HadGEM3-RA) with a $12.5 \mathrm{~km}$ resolution dataset but downscaled to hourly temperature data at $1 \mathrm{~km}$ spatial resolution for Korea by the MK-PRISM algorithm $[44,45]$. The HadGEM3-RA is derived by the boundary conditions of the historical run of the Atmosphere-Ocean coupled HadGEM2 contributed by the National Institute of Meteorological Sciences (NIMS) of Korea to the coordinated regional climate downscaling experiment (CORDEX) [46]. This is based on the representative concentration pathways (RCPs) 8.5 of the IPCC Fifth Assessment Report (AR5). The MK-PRISM performs well in estimating daily maximum temperature, daily mean temperature, daily minimum temperature, and daily precipitation, indicating that the PRISM may be useful as a bridging method for correcting the systematic bias of the dynamic model [45,47]. The simulation output for the reference period of 2000s (2001-2010) and the future period of the 2030s (2021-2030), 2050s (2041-2050), 2070s (2061-2070), and 2090s (2091-2100) were then evaluated to illustrate the climate impact on the goral habitat. 


\section{Results}

\subsection{Specific Distribution Pattern of Gorals}

The fecal deposits were categorized by three elevation ranges: $\leq 500 \mathrm{~m}, 501-900 \mathrm{~m}$, and $\geq 901 \mathrm{~m}$. Deposits were mostly found between 501 and $900 \mathrm{~m}$, accounting for 99 (88.4\%) and 49 (94.2\%) fecal samples in winter 2005 and summer 2006, respectively (Table 1). This range was defined as the elevation at which the goral spends most of its time for feeding and resting in this study. Only a few samples were found at elevations below $500 \mathrm{~m}$ or above $900 \mathrm{~m}$ (Table 1), which is similar to the findings of [26,31].

Table 1. Fecal deposit samples from the Seoraksan National Park during the winter of 2005 and the summer of 2006. The goral fecal samples were mostly found at 501-900 m of elevation indicating it usually inhibits at the elevation.

\begin{tabular}{ccccc}
\hline Sampling Date and Season & Ave. Temp. & Elevation (m) & \multicolumn{2}{c}{ No. of Deposits } \\
\hline Dec. 16 and 17, 2005 & $\mathrm{T}_{\mathrm{d} 16=-5.0^{\circ} \mathrm{C}}$ & $\geq 901$ & 9 & $8.0 \%$ \\
Winter (beginning) & $\mathrm{T}_{\mathrm{d} 17=-10.0{ }^{\circ} \mathrm{C}}$ & $501-900$ & 99 & $88.4 \%$ \\
& & $\leq 500$ & 4 & $3.6 \%$ \\
\hline & Subtotal & & 112 & $100 \%$ \\
\hline Jul. 4 and 6, 2006 & $\mathrm{T}_{\mathrm{d} 4}=20.0^{\circ} \mathrm{C}$ & $\geq 901$ & 0 & $0 \%$ \\
Summer (beginning) & $\mathrm{T}_{\mathrm{d} 6}=20.4{ }^{\circ} \mathrm{C}$ & $501-900$ & 49 & $94.2 \%$ \\
& & $\leq 500$ & 3 & $5.8 \%$ \\
\hline & Subtotal & & 52 & $100 \%$ \\
\hline & Total & & 164 & \\
\hline
\end{tabular}

\subsection{Sensitivity of the Model and Current Climate Conditions}

Using all required parameters for the simulation, climatic variables were extracted from the WRF simulation for the study area. The simulated hourly-based temperature values for the dates differ from the records the Inje weather station observations (Figure 4) but in mean values of daily temperature had a Pearson coefficient $=0.850989, p<0.01$, and sensitivity bias (multiplier) $=0.99956$ indicating that the simulation result was almost identical to the measured data. With the sensitivity test results, the current climatic condition at the goral habitat was defined like mean temperatures in 2006 (June) and 2005 (December) at 500-900 m elevation were 18.7 and $-8.3^{\circ} \mathrm{C}$, respectively (Figure 5). Additional conditions, for example, were shown that wind speeds were 1-5 and 4-8 m/s in summer and winter, respectively (Figure 5) and the directions were from the South (SW-ENE) and west (W-SSW), respectively. 


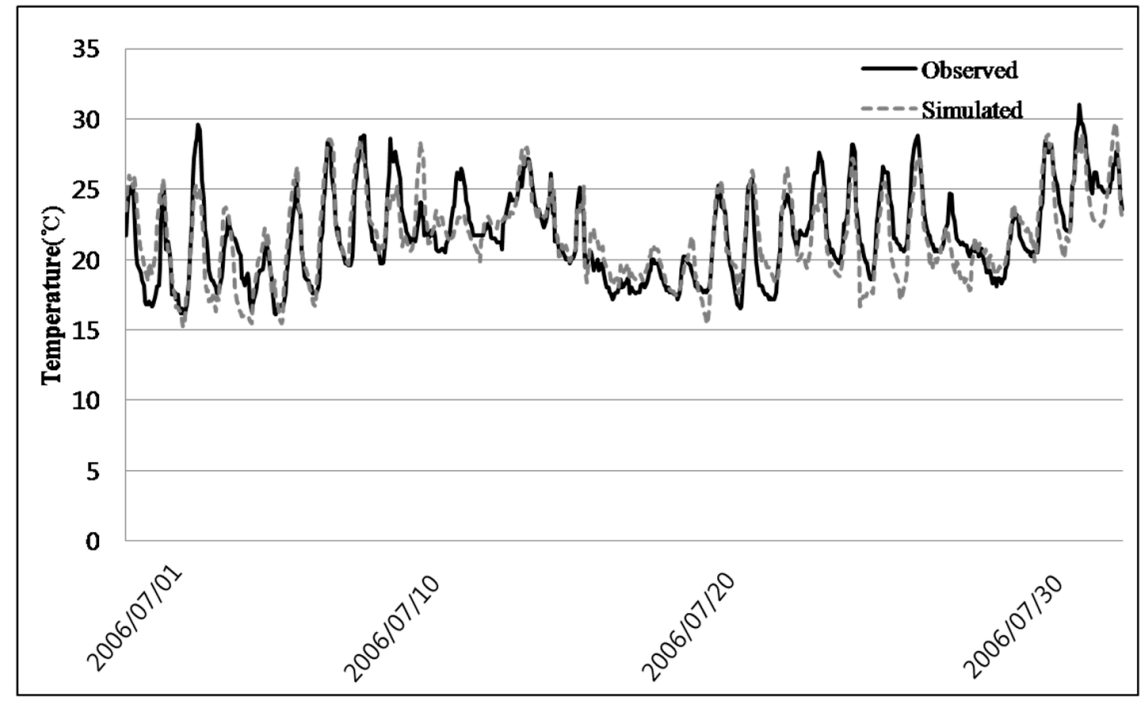

Figure 4. Comparison between hourly-based observed and simulated mean temperatures at the Inje weather station but the daily-based temperature matched to the observed data with the Pearson correlation coefficient of 0.88 and the bias of 1.0 wind speed $(\mathrm{m} / \mathrm{s})$.

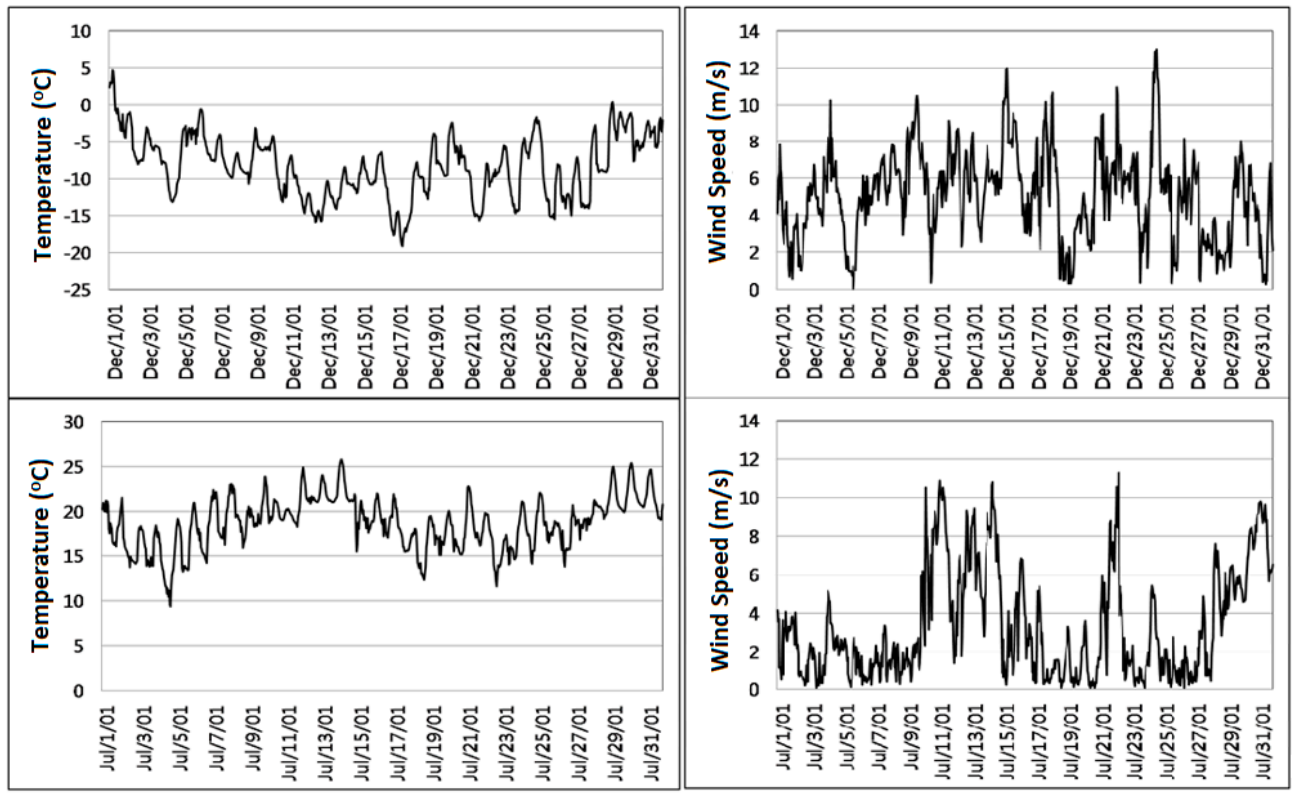

Figure 5. Temperature (left) and wind speed (right) patterns for winter 2005 (top) and summer 2006 (bottom) at the goral habitat where the fecal samples were located in Seoraksan National Park.

\subsection{Future Climate}

We used the climate change scenario with high spatial resolution from the MK-PRISM algorithm for the future goral habitat. Based on [45], the temperature bias of the algorithm was close to zero and Root Mean Squared Error (RMSE) of daily mean temperature was relatively small $\left(0.86{ }^{\circ} \mathrm{C}\right)$ indicating our simulation was reliable for analyzing future climate change assessment. Annual projected temperature based on RCP 4.5 and 8.5 scenarios increased to approximately $2.0^{\circ} \mathrm{C}$ and $4.9^{\circ} \mathrm{C}$ until the 2090s (Figure 6). On the basis of the result of RCP 8.5, a series of temperature changes was projected during the period from 2010s and 2090s for the suitable habitat of the goral. The suitable habitat (the blue colored area in Figure 7) for the Korean long-tailed goral at $18.7^{\circ} \mathrm{C}$ in summer and $-8.3^{\circ} \mathrm{C}$ in winter significantly declined and almost disappeared in the 2070s for summer and 2050s for winter. Such losses of suitable habitat may result in lower viability or greater possibility of extinction 
for the goral population in Seoraksan National Park. Note that the fecal locations were all included in the blue area in 2010s both in summer and winter.

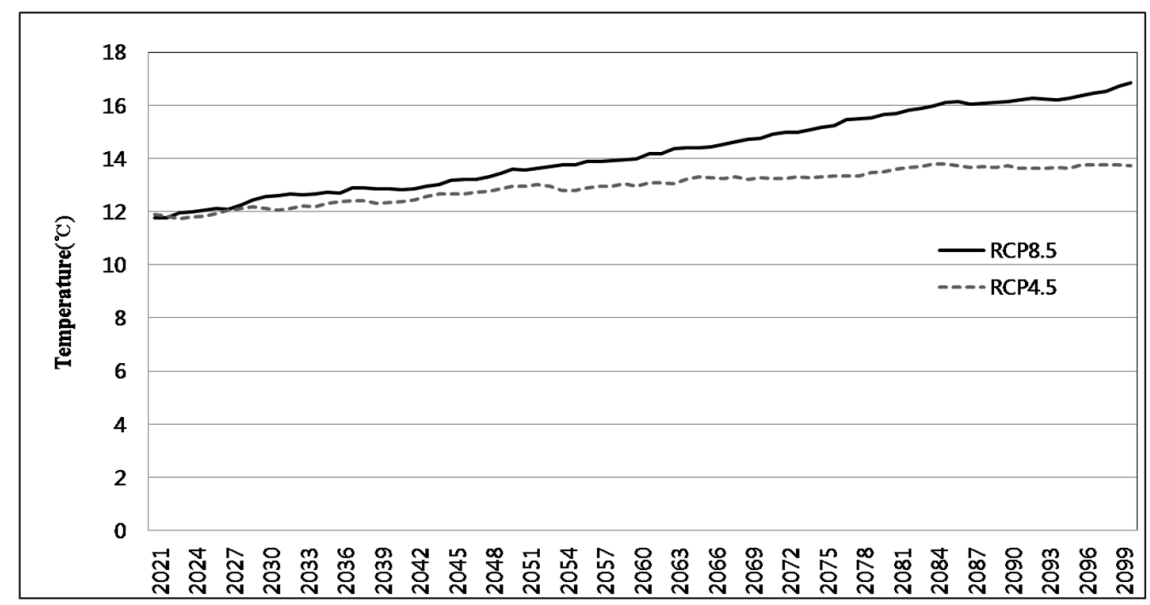

Figure 6. Annual projected temperature change based on the Modified Korean Parameter-elevation Regressions on Independent Slope Model (MK-PRISM) with the two scenarios of RCP 4.5 and 8.5 from 2021 to 2100 in Korea. 

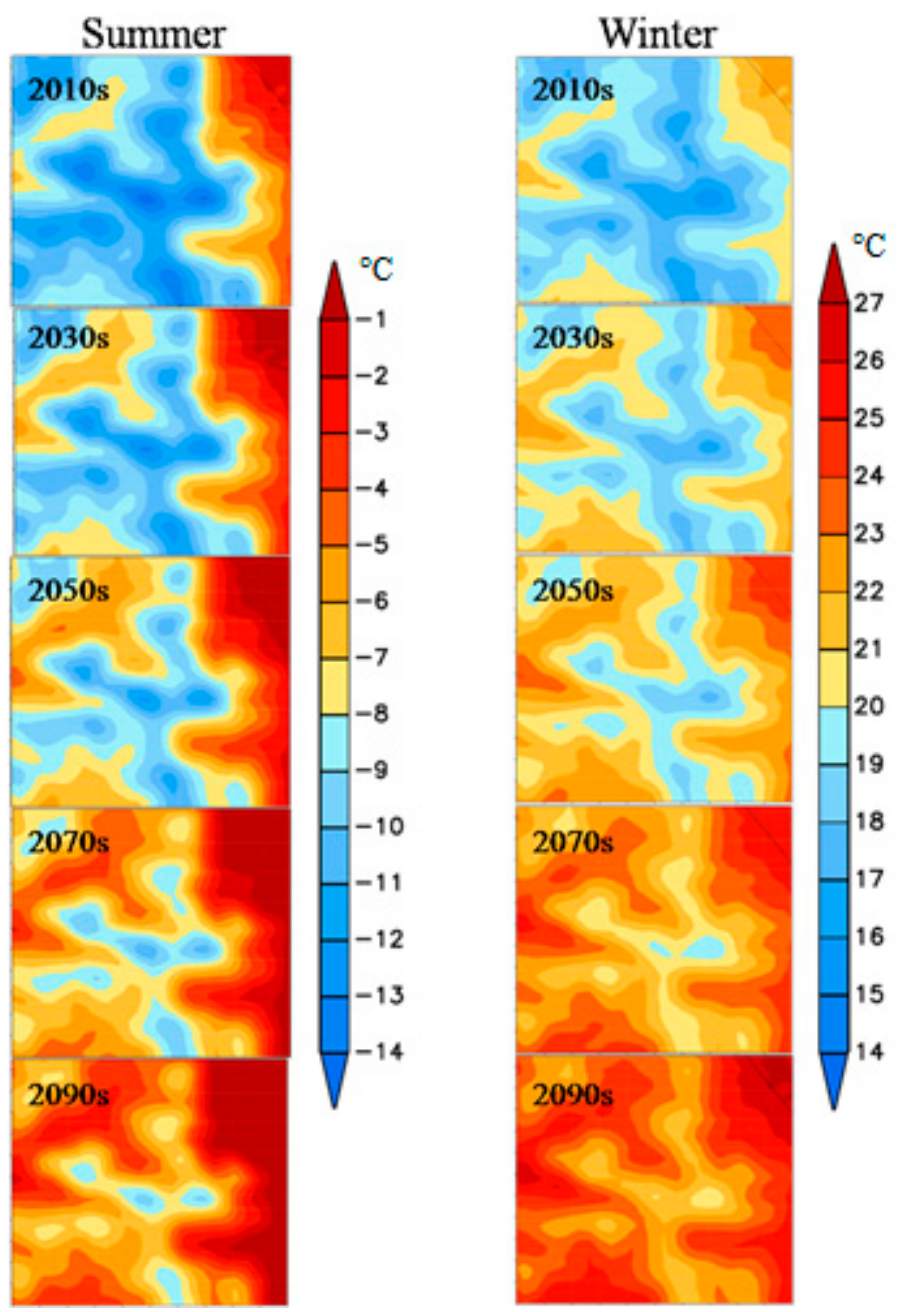

Figure 7. Projected future mean temperatures in $1 \mathrm{~km}$ grid for the currently fragmented goral habitat area in December (left) and June (right) in Seoraksan National Park. The habitat with the current temperature (the blue areas) will disappear approximately in the 2050s for winter and 2070s for summer.

\section{Discussion}

A single goral occupies a small range and usually does not travel far from its home territory. A research reported [39] showed that after a year of GPS tracking, the goral home ranges showed seasonal variations but the typical ranges were approximately 1.40 and $1.45 \mathrm{~km}^{2}$ at $95 \%$ level of accuracy with fixed kernel home range (FKHR) and minimum convex polygon (MCP) methods, respectively in Woraksan National Park, and 0.57 and $0.42 \mathrm{~km}^{2}$ at $95 \%$ level of accuracy with MCP and KHR, respectively in Seoraksan National Park. Based on the statistics of our fecal samples and other studies, the Korean long-tailed goral in Seoraksan National Park tend to prefer the middle elevation (501-900 $\mathrm{m}$ ) habitats (Table 1). The goral is a typical mountain ungulate species in South Korea. Historically, this species remained in mountainous areas for food and/or cover. Although the goral occasionally searches for food in lowland areas during periods of heavy winter snow, it normally feeds in its home territory [48]. Most of the higher regions of Seoraksan National Park consist of rocky areas in which food plants used by the goral decline with increasing elevation. For this reason, it would be difficult for the goral population to colonize very high or low elevations within the park.

The climatic conditions of the two seasons showed a different pattern. In summer 2006, mean temperature, relative humidity, and wind direction (speed) were $17.9{ }^{\circ} \mathrm{C}, 70 \%-95 \%$, and southerly $(1-5 \mathrm{~m} / \mathrm{s})$, respectively. In winter 2005, mean temperature, relative humidity, and wind direction (speed) were $-8.9^{\circ} \mathrm{C}, 60 \%-70 \%$, and westerly $(4-8 \mathrm{~m} / \mathrm{s})$, respectively. Since the goral currently 
lives in those climatic conditions, we could reasonably make an assumption that the current climatic conditions belong to the suitable habitat for the Korean long-tailed goral. Based on the present and projected climate conditions, therefore, the results from WRF can provide habitat ranges of the goral by delineating the areas of the current temperature. The application of WRF to habitat analysis can be helpful typically for very small and fragmented areas such as the endangered Korean long-tailed goral to understand the impact of climate change. The method evaluated the possible destiny of the goral habitat especially for an endangered species, which is difficult to be analyzed because of small habitat areas and populations.

For the assessment of the climate impact, we used only one variable, temperature. A comprehensive analysis would preferably include all possible variables including natural and human influences. However, the climatic factors affecting the goral population and habitat remain uncertain except for temperature, so we used that as a single variable to evaluate the change. More comprehensive research including vegetation, climate, and human need complex models.

\section{Conclusions}

The Korean long-tailed goral, one of the most endangered species registered in the IUCN Red List of Threatened Species and Convention on International Trade in Endangered Species (CITES) Appendix I, has been significantly diminished in numbers mainly due to human activities and now the habitat is fragmented and the population is reduced so that the sustainability of the goral is one of the critical issues in the environmental protection of Korea. Habitat analyses with climate scenarios are especially helpful providing useful information for scientists and policy makers. However, they are typically based on global climate scenario that is very difficult to implement in fragmented small areas for endangered species. Therefore, we applied a local climate simulation with WRF to examine the impact of climate change to the habitat for the Korean long-tailed goral.

WRF can downscale global climate datasets in coarse grid and fit the data to much smaller areas. The NCEP dataset with $1^{\circ}$ resolution was used to retrieve weather parameters with $1 \mathrm{~km}$ resolution for the study area. The parameters from WRF showed that the numerical model reproduced the current average climate conditions of the habitat of the goral in Seoraksan National Park with the sensitivity of Pearson coefficient $=0.850989, p<0.01$, and sensitivity bias (multiplier) $=0.99956$. Both the summer and winter climate patterns indicated that they could be applied to the analysis of goral habitat. By defining the current habitat from the result that was $18.7^{\circ} \mathrm{C}$ in summer and $-8.3^{\circ} \mathrm{C}$ in winter, the future climate simulation with the RCP 8.5 scenario produced a serious influence on the goral habitat by climate change in Korea. The projected temperature could cause a high risk of distinction of the Korean long-tailed goral habitat and we concluded that the current goral habitat would be significantly reduced within several decades and would disappear within the 2090s. In other words, the results suggest that the goral population could be severely affected by climate change, more specifically, by global warming.

In terms of the applicability of our approach, the simulation with WRF could provide species-specific information on habitat changes or range shifts at a local scale, which is very important for an endangered species with small fragmented habitat areas [48], and can be applied to the species even in the absence of demographic data. The development of more advanced methods (e.g., dynamical downscaling methods with much higher resolution and various climate scenarios) would allow climate conditions to be simulated with greater accuracy, thereby providing more reliable evaluation of climatic impacts on a species and habitat even at a small scale.

Author Contributions: Conceptualization, B.-J.K.; methodology, S.L.; software, S.L.; validation, S.L. and K.J.B.; formal analysis, S.L.; investigation, S.L. and K.J.B.; resources, S.L., B.-J.K. and K.J.B.; data curation, S.L. and K.J.B.; writing-Original draft preparation, B.-J.K. and S.L.; writing-Review and editing, K.J.B.; visualization, S.L.; supervision, K.J.B.; project administration, K.J.B.; funding acquisition, K.J.B.

Funding: This paper was funded by the general school research fund of Kumoh National Institute of Technology.

Conflicts of Interest: The authors declare no conflict of interest. 


\section{References}

1. Chapin, F.S.; Zavaleta, E.S.; Eviner, V.T.; Naylor, R.L.; Vitousek, P.M.; Reynolds, H.L.; Hooper, D.U.; Lavorel, S.; Sala, O.E.; Hobbie, S.E.; et al. Consequences of changing biodiversity. Nature 2000, 405, 234-242. [CrossRef] [PubMed]

2. Pounds, J.A.; Puschendorf, R. Clouded futures. Nature 2004, 427, 107-109. [CrossRef] [PubMed]

3. Thomas, C.D.; Cameron, A.; Green, R.E.; Bakkenes, M.; Beaumont, L.J.; Collingham, Y.C.; Erasmus, B.F.N.; de Siqueira, M.F.; Grainger, A.; Hannah, L.; et al. Extinction risk from climate change. Nature 2004, 427, $145-148$. [CrossRef] [PubMed]

4. Araujo, M.; Rahbek, C. How does climate change affect biodiversity? Science 2006, 313, 1396-1397. [CrossRef]

5. Hutton, J.; Dickson, B. Endangered Species, Threatened Convention: The Past, Present and Future of CITES; Earthscan Publications: London, UK, 2000.

6. Parmesan, C.; Yohe, G. A globally coherent fingerprint of climate change impacts across natural systems. Nature 2003, 421, 37-42. [CrossRef]

7. Root, T.L.; Price, J.T.; Hall, K.R.; Schneider, S.H.; Rosenzweig, C.; Pounds, J.A. Fingerprints of global warming on wild animals and plants. Nature 2003, 421, 57-60. [CrossRef]

8. Moritz, C.; Patton, J.L.; Conroy, C.J.; Parra, J.L.; White, G.C.; Beissinger, S.R. Impact of a century of climate change on small-mammal communities in Yosemite national park, USA. Science 2008, 322, 261-264. [CrossRef]

9. Hunter, C.M.; Caswell, H.; Runge, M.C.; Regehr, E.V.; Amstrup, S.C.; Stiring, I. Climate change threatens polar bear populations: A stochastic demographic analysis. Ecology 2010, 91, 2883-2897. [CrossRef]

10. Bellard, C.; Bertelsmeier, C.; Leadley, P.; Thuiller, W.; Courchamp, F. Impacts of climate change on the future of biodiversity. Ecol. Lett. 2012, 15, 365-377. [CrossRef]

11. Sutton, W.B.; Barrett, K.; Moody, A.T.; Loftin, C.S.; de Maynadier, P.G.; Nanjappa, P. Projected changes in climatic niche and climate refugia of conservation priority salamander species in the northeastern United States. Forests 2015, 6, 1-26. [CrossRef]

12. Sugden, A.M. Consequences of shifting species distributions. Science 2017, 355, 1386-1388. [CrossRef] [PubMed]

13. Ashrafzadeh, M.R.; Naghipour, A.A.; Haidarian, M.; Khorozyan, I. Modeling the response of an endangered flagship predator to climate change in Iran. Mammal Res. 2019, 64, 39-51. [CrossRef]

14. Velo-Anton, G.; Parra, J.L.; Parra-Olea, G.; Zamudio, K.R. Tracking climate change in a dispersal-limited species: Reduced spatial and genetic connectivity in a montane salamander. Mol. Ecol. 2013, 22, 3261-3278. [CrossRef] [PubMed]

15. Early, R.; Sax, D.F. Climatic niche shifts between species' native and naturalized ranges raise concern for ecological forecasts during invasions and climate change. Glob. Ecol. Biogeogr. 2014, 23, 1356-1365. [CrossRef]

16. Kusza, S.; Nagy, K.; Lanszki, J.; Heltai, M.; Szabo, C.; Czarnomska, S.D. Moderate genetic variability and no genetic structure within the European golden jackal (Canis aureus) population in Hungary. Mammal Res. 2019, 64, 63-69. [CrossRef]

17. Thuiller, W. Climate change and the ecologist. Nature 2007, 448, 550-552. [CrossRef]

18. Intergovernmental Panel on Climate Change (IPCC). Climate Change 2014 Mitigation of Climate Change. In Working Group III Contribution to the Fifth Assessment Report of the Intergovernmental Panel on Climate Change; Cambridge University Press: Cambridge, UK, 2014.

19. Wilkening, J.; Pearson-Prestera, W.; Nungi, N.A.; Bhattacharyya, S. Endangered species management and climate change: When habitat conservation becomes a moving target. Wildl. Soc. Bull. 2019, 43, 11-20. [CrossRef]

20. Mestre, F. Synergistic Effects of Climate Change and Habitat Fragmentation on Species Range Shifts and Metapopulation Persistence. Ph.D. Thesis, University of Évora, Évora, Portugal, 2017.

21. Huntley, B.; Collingham, Y.C.; Gree, R.E.; Hilton, G.M.; Rahbek, C.; Willis, S.G. Potential impacts of climatic change upon geographical distributions of birds. Spec. Issue Wind. Water Renew. Energy Birds 2006, 148, 8-28. [CrossRef]

22. Hijmans, R.J.; Graham, C.H. The ability of climate envelope models to predict the effects of climate change on species distributions. Glob. Clim. Chang. 2006, 12, 2272-2281. [CrossRef]

23. Songer, M.; Delion, M.; Biggs, A.; Huang, Q. Modeling impacts of climate change on giant panda habitat. Int. J. Ecol. 2012, 2012, 108752. [CrossRef] 
24. Convention on International Trade in Endangered Species (CITES) of Wild Fauna and Flora. Available online: https://www.cites.org/eng/app/appendices.php (accessed on 26 September 2019).

25. The IUCN Red List of Threatened Species. Available online: https://www.iucnredlist.org/species/14295/ 4429742 (accessed on 26 September 2019).

26. Yang, B.G. Systematics, Ecology and Current Population Status of the Goral, Naemorhedus caudatus, in Korea. Ph.D. Thesis, Chungbuk National University, Cheongju, Korea, 2002.

27. Cho, C.U.; Kim, K.C.; Gyun, G.H.; Kim, K.Y.; Lee, B.K.; Son, J.I. Habitat use of reintroduced long-tailed gorals (Naemorhedus caudatus) in Woraksan (Mt.) National Park in Korea. Korean J. Environ. Ecol. 2015, 29, 185-192. [CrossRef]

28. Won, P.H. The Illustrated Encyclopedia of Fauna and Flora of Korea; Minister of Education: Seoul, Korea, 1967; pp. 59-65.

29. Kim, D.B.; Koo, K.A.; Kim, H.H.; Hwang, G.Y.; Kong, W.S. Reconstruction of the habitat range suitable for long-tailed goral (Naemorhedus caudatus) using fossils from the Paleolithic Sites. Quat. Int. 2019, 519, 101-112. [CrossRef]

30. Cho, C.U. Systematic Study on the Long-Tailed Goral (Naemorhedus caudatus), with Ecology and Conservation Plan. Ph.D. Thesis, Chungbuk National University, Gheongju, Korea, 2013.

31. Cho, C.U.; Kim, K.C.; Kwon, G.H.; Kim, K.Y.; Lee, B.K.; Song, B.C.; Park, J.G. Current status of population size and habitat selection of the long-tailed goral (Naemorhedus caudatus) in Seoraksan National Park. Korean J. Environ. Ecol. 2015, 29, 710-717. [CrossRef]

32. Mishra, C.; Johnsingh, A.J.T. On habitat selection by the goral Nemorhaedus goral bedfordi (Bovidae, Artiodactyla). J. Zool. 2009, 240, 573-580. [CrossRef]

33. Choi, T.Y.; Park, J.H. Establishing a Korean goral (nemorhaedus cuadatus raddeanus heud) reserve in Soraksan National Park, Korea. J. Korean Inst. Landsc. Archit. 2005, 32, 23-35.

34. Wang, Y.Q.; Leung, L.R.; McGregor, J.L.; Lee, D.K.; Wang, W.C.; Ding, Y.H.; Kimura, F. Regional climate modeling: Progress, challenges, and prospects. J. Meteorol. Soc. Jpn. 2004, 82, 1599-1628. [CrossRef]

35. Kain, J.S.; Fritsch, J.M. Convective Parameterization Fir Mesoscale Models: The Kain-Fritsch Scheme. In The Representation of Cumulus Convection in Numerical Models; Emanuel, K.A., Raymond, D.J., Eds.; American Meteorological Society: Boston, MA, USA, 1993; pp. 165-170.

36. IPCC. Contribution of Working Groups I, II, and III to the Fifth Assessment Report of the Intergovernmental Panel on Climate Change; Climate Change: Synthesis Report; IPCC: Geneva, Switzerland, 2014; p. 151.

37. Murphy, J. An evaluation of statistical and dynamical techniques for downscaling local climate. J. Climatol. 1999, 12, 2256-2284. [CrossRef]

38. Wood, A.W.; Leung, L.R.; Sridhar, V.; Lettenmaier, P. Hydrologic implications of dynamical and statistical approaches to down-scaling climate model outputs. Clim. Chang. 2004, 62, 233-256. [CrossRef]

39. Hong, S.Y.; Lim, J.O.J. The WRF single-moment 6-class microphysics scheme (WSM6). J. Korean Meteorol. Soc. 2006, 42, 129-151.

40. Hong, S.Y.; Lim, K.; Kim, J.; Lim, J.; Dudhia, J. Sensitivity study of cloud resolving convective simulations with WRF using two bulk microphysical parameterizations: Ice-phase microphysics versus sedimentation effects. J. Appl. Meteorol. Climatol. 2008, 48, 61-76. [CrossRef]

41. Hong, S.Y.; Lee, J.W. Assessment of the WRF model in reproducing a flash-flood heavy rainfall event over Korea. Atmos. Res. 2009, 93, 818-831. [CrossRef]

42. Mellor, G.L.; Yamada, T. Development of a turbulence closure model for geophysical fluid problems. Rev. Geophys. Space Phys. 1982, 20, 851-875. [CrossRef]

43. Janjic, Z.I. Nonsingular implementation of the Mellor-Yamada Level 2.5 scheme in the NCEP Meso model. NCEP Off. Note 2002, 437, 61.

44. Kim, M.K.; Lee, D.H.; Kim, J. Production and validation of daily grid data with $1 \mathrm{~km}$ resolution in South Korea. J. Clim. Res. 2013, 8, 13-25.

45. Kim, M.K.; Kim, S.; Kim, J.; Heo, J.; Park, J.S.; Kwon, W.T.; Suh, M.S. Statistical downscaling for daily precipitation in Korea using combhined PRISM, RCM, AND Quantile mapping: Part 1, Methodlolgy and Evaluation in Historical Simulation. Asia Pac. J. Atmos. Sci. 2016, 52, 79-89. [CrossRef]

46. Baek, H.J.; Lee, J.; Lee, H.S.; Hyun, Y.K.; Cho, C.H.; Kwon, W.T.; Marziin, C.; Gan, S.Y.; Kim, M.J.; Choi, D.H.; et al. Climate change in the 21st century simulated by HadGEM2-AO under representative concentration pathways. Asia Pac. J. Atmos. Sci. 2013, 49, 603-618. [CrossRef] 
47. Lee, S.; Bae, D.H. Local effects of climate change over South Korea with a high-resolution climate scenario. Clim. Res. 2012, 54, 85-93. [CrossRef]

48. Won, C.M.; Smith, K.G. History and current status of mammals of the Korean peninsula. Mammal Rev. 1999, 29, 3-36. [CrossRef]

(C) 2019 by the authors. Licensee MDPI, Basel, Switzerland. This article is an open access article distributed under the terms and conditions of the Creative Commons Attribution (CC BY) license (http://creativecommons.org/licenses/by/4.0/). 